\title{
CULTIVO DE OSTEOCLASTOS PORCINOS Y SU ACCIÓN BIOLÓGICA EN LÁMINAS DE POLIETILENO DE BAJA DENSIDAD Y APATITA CARBONATADA
}

\author{
Claudia Bernalin, Bacterióloga, Martha Lucía Torresin, Microbióloga M.Sc., \\ William Oliverosi, M.D., Ismail Zainol', Ciencia de Materiales, Ph.D, \\ Fadzil Ayad Zakaria², Ciencia de Materiales, Ph.D., José Mikán'i Biólogo, Ph.D. \\ ${ }^{1}$ Grupo Biotecnología en Salud, Laboratorio de Investigaciones, Facultad de Medicina, Universidad \\ Militar Nueva Granada, Bogotá, Colombia. ${ }^{2}$ Biomaterials Programme, Advanced Materials Research Centre \\ (AMREC), SIRIM Berhad, Lot 34, Jalan Hi-Tech 2/3, Kulim Hi-Tech Park, 09000 Kulim, Kedah, Malaysia.
}

\begin{abstract}
Resumen
El hueso es un tejido en constante cambio por procesos de remodelación y reparación, funciones realizadas por tres tipos celulares: los osteoblastos, los osteocitos y los osteoclastos. Los osteoclastos (OC) son células grandes, multinucleadas y ricas en anhidrasa carbónica y fosfatasa ácida resistente al tartrato (TRAP). Continuando con trabajos previos en los cuales se ha sintetizado apatita carbonatada (CAp) por precipitación de soluciones acuosas y por reacción del estado sólido, en este artículo se presentan los resultados del cultivo de osteoclastos y su efecto biológico sobre láminas sintetizadas de polietileno de baja densidad y CAp (PEBD-CAp). La inducción al linaje osteoclastogénico se realizó adicionando inductores específicos a cultivos de progenitores de la medula ósea de porcinos, a los que se les determinó la actividad de TRAP y la detección de los transcritos de los genes rank, c-src y cat-K. El cultivo sobre láminas PEBD-CAp permitió evidenciar la actividad osteoclástica sobre la cerámica a través de microscopia óptica y electrónica, demostrando su biodegradabilidad in vitro y complementando resultados previos sobre la osteoconductividad del material en un modelo in vivo en porcinos.
\end{abstract}

Palabras clave: apatita carbonatada, polietileno de baja densidad, osteoclastos, resorción ósea

\section{PORCINE OSTEOCLAST CULTURE AND ITS BIOLOGICAL ACTION ON COMPOSITE SLIDES OF CARBONATED APATITE AND LOW DENSITY POLYETHYLENE (LDPE)}

\begin{abstract}
Bone tissue is in a continuous process of synthesis and resorption, functions that are performed by three main cell types: osteblasts, osteocytes and osteoclasts. Osteoclasts $(\mathrm{OC})$ are big, multinucleate cells, producing carbonic anhydrase and tartrate-resistant acid phosphatase (TRAP). In continuation with previous works where CAp was synthesised by precipitation of aqueous solution and by solid state reaction, in this article the results of a culture of osteoclasts and its biological action over low-density polyethylene impregnated with carbonated apatite slides (LDPE-CAp) are shown. Osteoclast induction was achieved with the addition of specific inductors to cultures of porcine bone marrow progenitors, to which TRAP activity, detection of transcripts of rank, $c$-src and cat-K genes were determined. Cultures on LDPE-CAp slides analyzed with optical and electron microscopy demonstrated osteoclast activity
\end{abstract}

* Correspondencia: José Mikán jose.mikan@unimilitar.edu.co. Dirección Correspondencia: Laboratorio de investigaciones, Facultad de Medicina, Universidad Militar Nueva Granada, Tr. 3a \#49-00, Bogotá, Colombia.

Recibido: Mayo 10 de 2010 Aceptado: Junio 14 de 2010. 
and biodegradability of the ceramic, thus complementing previous studies on the osteoconductivity of this material in an in vivo porcine model.

Keywords: carbonated apatite, low-density polyethylene, osteoclasts, bone resorption

\author{
CULTURA DE OSTEOCLASTOS DE SUÍNOS \\ E SUA AÇÃO BIOLÓGICA EM FILMES DE POLIETILENO \\ DE BAIXA DENSIDADE E APATITA CARBONATADA
}

\title{
Resumo
}

\begin{abstract}
O tecido ósseo está em constante mutação através dos processos de remodelação e reparação, funções executadas por três tipos de células: osteoblastos, osteócitos e osteoclastos. Osteoclastos (OC) são células grandes, multinucleadas e ricas em anidrase carbônica $e$ fosfatase ácida resistente ao tartarato (TRAP). Na sequência dos trabalhos previos nos quais foi sintetizado apatita carbonatada (CAP) por precipitação a partir de soluções acuosas e reação em estado sólido, este artigo apresenta os resultados a cultura dos osteoclastos e seu efeito biológico sobre filmes sintetizados de polietileno de baixa densidade e Cap (PEBD-Cap). A indução da linhagem osteoclastogénico foi feito pela adição de indutores específicas a culturas progenitoras da medula óssea de porcos, nos quais foi determinada a atividade TRAP e a deteção de transcritos dos genes rank, $c$-src e cat-K. O cultivo em placas PEBD-Cap permitiu demonstrar a atividade osteoclástica em cerâmica por microscopia óptica e eletrônica, demosntrando a sua biodegradabilidade in vitro e complementando resultados anteriores sobre a osteocondutividade do material em um modelo de suínos in vivo.
\end{abstract}

Palavras-chave: apatita carbonatada, polietileno de baixa densidade, osteoclastos, reabsorção óssea

\section{Introducción}

El hueso esta compuesto fundamentalmente por material orgánico, en su mayoría fibras de colágeno (34\% en volumen) y material inorgánico, principalmente fosfato de calcio apatítico $\left(\mathrm{Ca}_{10}\left(\mathrm{PO}_{4}\right)_{6}(\mathrm{OH})_{2}\right)$, otros componentes minerales, especialmente carbonato, los cuales se presentan como cristales de orden nanométrico ( $42 \%$ en volumen) y agua ( $24 \%$ en volumen). Se trata de un material biológico, organizado jerárquicamente en una arquitectura compleja en la cual se pueden distinguir distintos niveles. Por ser un tejido vivo está en constante cambio por procesos de remodelación y reparación, funciones realizadas por los osteoblastos, los osteocitos y los osteoclastos. Los osteoclastos (OC) son células grandes, multinucleadas y ricas en anhidrasa carbónica y fosfatasa ácida resistente al tartrato (TRAP) y se localizan sobre las superficies óseas de manera aislada o en grupos poco numerosos $(1,2)$.

Los preosteoclastos son células con un solo núcleo y expresan en su membrana moléculas de adhesión per- tenecientes a la familia de las caderinas, cuya función parece ser promover en la fusión de estas células y así formar los OC. Los OC se originan a partir de células formadoras de colonias de granulocitos y macrófagos (GM-CSF), derivadas a su vez de precursores mono nucleares que se originan de células madre hematopoyéticas (CD34+). La activación de la proliferación de progenitores GM-CSF es promovida por la IL-1, IL-6 e IL-11 entre otras. Los precursores de los osteoclastos poseen en su superficie el receptor c-FMS el cual interactúa con el M-CSF (factor estimulante de colonias de macrófago) cuya función es promover la proliferación y sobrevida de estos precursores. En este linaje celular algunas células que expresan c-fos (pre-osteoclastos) se diferencian a osteoclastos, y las otras en macrófago por la activación de la vía de señalización del receptor RANK-RANK-L $(3,4,5)$.

Los OC son los encargados de la resorción del hueso, para lo cual se adhieren a la superficie ósea por la llamada zona de sellado (sealing zone), que rodea el borde en cepillo y en este proceso la presencia de 
receptores de vitronectina (integrina $\alpha_{\mathrm{v}} \beta_{3}$ ) es crítica, los cuales reconocen la secuencia de aminoácidos RGD (arginina-glicina-aspartato), presente en diversas proteínas de la matriz (6). En la zona de contacto del osteoclasto con el mineral óseo, se forma un espacio en el que se liberan grandes cantidades de hidrogeniones y enzimas lisosomales, que disuelven los cristales de hidroxiapatita y degradan las proteínas de la matriz $(5,7,8,9)$.

En los últimos años se ha venido trabajando en ingeniería de tejidos para el desarrollo de materiales sintéticos, que en conjunto con células de tejido específico, puedan reemplazar los injertos naturales y en el caso específico de substitutos óseos, se buscan implantes que tengan la capacidad de promover la regeneración o reparación de tejido propio a partir de células madre mesenquimales $(10,11)$. Complementario a esto se está utilizando la síntesis química que permite la creación de materiales bien caracterizados físico-químicamente, los cuales deben ser evaluados in vitro con cultivos celulares e in vivo en animales de experimentación, antes de realizar los estudios clínicos en humanos. En la evaluación in vitro se puede evidenciar la compatibilidad biológica y la biofuncionalidad del material antes de utilizarlo como implante; en este tipo de estudio lo que se analiza es si tiene propiedades similares a las del órgano que reemplaza $(12,13)$.

Para producir un material que cumpliera con las funciones descritas anteriormente, se sintetizó apatita carbonada (CAp) por precipitación de soluciones de precursores y por reacción del estado sólido. Para evaluarlo, se estableció un cultivo de osteoblastos provenientes de células osteoprogenitoras del periostio y de la médula ósea de porcinos, cuyos resultados fueron ya publicados (10,11,14-16). En este artículo se muestran los resultados del cultivo de osteoclastos derivados de células progenitoras de la médula ósea de porcino y de su actividad osteoclástica cuando son cultivados sobre CAp dispersa en láminas de capa delgada de polietileno de baja densidad (PEBD).

\section{Materiales y métodos}

\section{Preparación de polvo de apatita carbonatada (CAp)}

Se preparó polvo de CAp por precipitación a partir de la mezcla de dos soluciones: $1,0 \mathrm{M}$ de $\mathrm{Ca}\left(\mathrm{NO}_{3}\right)_{2} \cdot 4 \mathrm{H}_{2} \mathrm{O}$ y $0,6 \mathrm{M}_{\text {de }} \mathrm{H}_{3} \mathrm{PO}_{4}$, las cuales se combinaron por goteo en una tercera solución $0,7 \mathrm{M} \mathrm{NaHCO}_{3}$. La mezcla se realizó a $40^{\circ} \mathrm{C}$ con agitación continua y manteniendo el $\mathrm{pH}$ neutro con $\mathrm{NH}_{4} \mathrm{OH}$. Una vez terminada la mezcla se obtuvo una suspensión que se dejó precipitar por 24 h. El precipitado se filtró, se lavó con agua desionizada, se secó a $50^{\circ} \mathrm{C}$ y finalmente se paso por un colador para separar el polvo.

\section{Fabricación de CAp dispersada en láminas de polietileno de baja densidad (PEBD)}

Se fabricaron láminas por mezcla de PEBD $(85 \% \mathrm{p} / \mathrm{v})$ y polvo de CAp ( $15 \% \mathrm{p} / \mathrm{v})$ en un mezclador interno (Thermo Haake PolyDrive - Rheomix R600/610). La mezcla fue prensada en calor (Flowmech) a $160^{\circ} \mathrm{C}$ en un molde de aluminio a una presión de $100 \mathrm{~kg} / \mathrm{cm}^{2}$. El bloque obtenido fue cortado en láminas de $6 \times 6 \times 1,5$ mm usando un cortador de precisión de punta de diamante.

Obtención y cultivo de células progenitoras a partir de medula ósea de porcino

Las células de médula ósea fueron obtenidas de la cresta iliaca de porcinos, de acuerdo a la metodología descrita por Carretero y Col. (2009) (11). Las células mononucleares fueron separadas por gradientes de densidad, se cultivaron $14 \times 10^{4}$ células por $\mathrm{cm}^{2}$ en el medio 60:40, (60\% de medio Dulbeco modificado por Eagle (DMEM) (Gifco) y 40\%(v/v) de medio complemento con trazas de elementos (MCDB-2001) (Sigma)) suplementado con suero fetal bovino (SFB, Eurobio) al $10 \%(\mathrm{v} / \mathrm{v})$ y se incubaron a $37^{\circ} \mathrm{C}$ en atmósfera húmeda y $5 \%$ de $\mathrm{CO}_{2}$. Se realizaron cambios cada tercer día de cultivo con medio suplementado con SFB, cuya concentración se disminuyó gradualmente hasta llegar al $2 \%(\mathrm{v} / \mathrm{v})$. Luego se realizaron subcultivos hasta observar cambios morfológicos (tamaño, forma y adhesión) característicos de estas células, siendo semejantes a las de las células mesenquimales. Luego se almacenaron en nitrógeno líquido hasta su uso (10).

\section{Diferenciación osteoclástica}

Después de descongelar las células se cultivaron en medio 60:40 más $2 \%$ de SFB hasta alcanzar una confluencia del $80 \%$ en placas de 24 pozos, luego se separaron con tripsina y se subcultivaron en cinco grupos diferentes en placas de cultivo de 48 pozos, todos con medio 60:40 más 2\% SFB, así: (1) Control de inducción: pozos con medio de cultivo; (2) Control de material: pozos conteniendo una lámina de Thermanox ${ }^{\circledR}$ 
cover slips (Th); (3) Inducción: pozos conteniendo una lámina Th, $10 \mathrm{ng} / \mathrm{ml}$ de M-CSF, (Sigma) y $100 \mathrm{ng} / \mathrm{ml}$ del ligando del receptor activador del factor nuclear-kB o RANKL, (Sigma); (4) Material: pozos conteniendo una lamina PEBD-CAp; (5) Inductores y material: pozos conteniendo una lámina PEBD-CAp, $10 \mathrm{ng} / \mathrm{ml}$ M-CSF y $100 \mathrm{ng} / \mathrm{ml}$ RANKL. Además se cultivaron células de la línea de macrófagos adherentes U937 (ATCC) y una línea de fibroblastos (ATCC) sobre Th y PEBD (sin CAp) en medio de diferenciación, para usarlos como controles positivo y negativo, respectivamente, en la caracterización bioquímica y molecular, así como controles en microscopia electrónica de barrido. Todos los grupos se cultivaron durante diez días por triplicado y se les hizo cambio de medio cada tercer día. Se realizaron coloraciones de hematoxilina-eosina sobre Th y láminas PEBD-CAp, para visualizar la formación de células gigantes en los cultivos inducidos.

\section{Actividad de la fosfatasa ácida resistente a tartrato (TRAP)}

Los cultivos celulares se fijaron con formaldehído al $3 \%$ en buffer fosfato salino (PBS) por 15 minutos y se lavaron con PBS tres veces. La actividad de TRAP, que se considera como un marcador del fenotipo osteoclástico (17), fue detectada por microscopia de luz usando el kit comercial de Sigma-Aldrich No 386.

\section{Detección de marcadores moleculares}

La extracción de mARN a partir de todos los cultivos de células se realizó por el método de trizol (Gibco-BRL Life Technologies cat No.15526). Así, para 1-5 millones de células se adicionó $500 \mu \mathrm{L}$ de trizol, se incubó a temperatura ambiente por cinco minutos, luego se adicionó $100 \mu \mathrm{L}$ de cloroformo y se dejó a temperatura ambiente por tres minutos. Después de centrifugar a $12000 \mathrm{~g}$ por 15 minutos a $4^{\circ} \mathrm{C}$, se adicionó a la parte acuosa $250 \mu \mathrm{L}$ de isopropanol, se centrifugó a 12000 x g por 10 minutos a $4^{\circ} \mathrm{C}$ y el precipitado se resuspendió en $500 \mu \mathrm{L}$ de etanol al $75 \%$. Se centrifugó a 7500 x g por 5 minutos a $4^{\circ} \mathrm{C}$ y el precipitado se re-suspendió en $40 \mu \mathrm{L}$ de agua libre de RNasas y se guardó a $-70^{\circ} \mathrm{C}$ hasta su uso.

Para la síntesis de cADN se utilizaron $200 \mathrm{U} / \mu \mathrm{L}$ de la enzima transcriptasa reversa SuperScript II (INVITROGEN cat No. 18064-022). Así: $1 \mu$ L Oligo-dT $(500 \mu \mathrm{g} / \mathrm{mL}), 10 \mu \mathrm{L}$ de ARN y $4 \mu \mathrm{L}$ de agua ultra pura. Esta mezcla se incubó a $65^{\circ} \mathrm{C}$ por 15 minutos.
Luego se adicionó $1,25 \mu \mathrm{L}$ de dNTP's (10 mM), 1 $\mu \mathrm{L}$ de RNasa OUT (INVITROGEN cat No. 10777019), $5 \mu \mathrm{L}$ de Buffer $5 \mathrm{X}$ primera hebra (250 mM Tris- $\mathrm{HCl} \mathrm{pH} \mathrm{8,3,} 375 \mathrm{mM} \mathrm{KCl}, 15 \mathrm{mM} \mathrm{MgCl} 2)$ y 1 $\mu \mathrm{L}$ de transcriptasa reversa SuperScript II, $1,25 \mu \mathrm{L}$ de agua ultra pura y se dejó a $42^{\circ} \mathrm{C}$ por 50 minutos y $70{ }^{\circ} \mathrm{C}$ por 15 minutos.

La amplificación se realizó en un termociclador Eppendorff. Primero se establecieron las condiciones para cada par de primers y luego se amplificaron los genes de la $\beta$-actina y de los marcadores de la línea de osteoclastos tales como rank (que codifica el receptor RANK), c-src (que codifica la tirosina-quinasa citoplasmática) y cat- $K$ (que codifica para la proteasa catepsina-K). Como control negativo se utilizó el cADN de las células de un cultivo de fibroblastos. Las secuencias de los primers específicos se diseñaron a partir del alineamiento de secuencias de aminoácidos y correspondientes nucleótidos de diferentes especies con el programa Multiple Sequence Aligment-Clustal W (biology work bench en: http://workbench.sdssc.edu).

TABLA 1. Secuencias de los primers específicos para marcadores moleculares de osteoclastogénesis

\begin{tabular}{|c|c|c|c|}
\hline \multicolumn{2}{|c|}{$\begin{array}{l}\text { cADN } \\
\text { blanco }\end{array}$} & Secuencias de los primers & \multirow{3}{*}{$\begin{array}{c}\begin{array}{c}\text { Tamaño } \\
\text { del } \\
\text { producto } \\
\text { de PCR } \\
\text { esperado }\end{array} \\
305 \mathrm{pb}\end{array}$} \\
\hline \multirow{2}{*}{$b$-actina } & 5 & TCCCTGTACGCCTCTGGCCG & \\
\hline & 3 & CAGCTCGTAGCTCTTCTCCA & \\
\hline cat $k F w$ & 5 & TTCCCGCAGTAATGACACC & \multirow{2}{*}{$615 \mathrm{pb}$} \\
\hline cat $k R v$ & 5 & TT(G/A)CCCCAGTTTTCTCCСC & \\
\hline $\operatorname{rank} F w$ & 5 & AGTGT(A/G)TGTCTGCCCTGTGG & \multirow{2}{*}{$528 \mathrm{pb}$} \\
\hline $\operatorname{rank} R v$ & 5 & CCACAAATTAGCTGT(G/T)AG & \\
\hline$c$-src Fw & 5 & GCCTTTGGGAAGGTGGT(A/G)GAG & \multirow{2}{*}{$336 \mathrm{pb}$} \\
\hline$c$-src $R v$ & 5 & TGGAGAAGCCACTGTCCCT & \\
\hline
\end{tabular}

Fw: forward; Rv: reverse

\section{Microscopía Electrónica de Barrido (SEM)}

Se realizó SEM a todos los cultivos utilizando el método reportado por Hing y col (13). Para la preparación de muestras se realizó una deshidratación con acetona a concentración ascendente $(30 \%, 50 \%, 70 \%, 90 \%$, $100 \%$ y $100 \%$ ) y las observaciones se hicieron en el 
microscopio electrónico de barrido XVP (eXtended Variable Pressure), Zeiss EVO LS 10, Germany (11).

\section{Resultados}

A partir de los cultivos de células mononucleares se obtuvieron células adherentes que proliferaron hasta presentar una morfología fibroblastoide y un tamaño como el que se describe y se muestra para las células mesenquimales (Figura 1A). En los cultivos inducidos con M-CSF y RANKL se observaron a los tres días células TRAP positivas con tres núcleos o más (Figura1B), características que definen a los osteoclastos y que son mas evidentes en el día diez de cultivo (Figura $1 C)$; estas características también fueron observadas en las células del cultivo de la línea celular de macrófagos utilizado como control positivo (Figura 1D), inducida

A

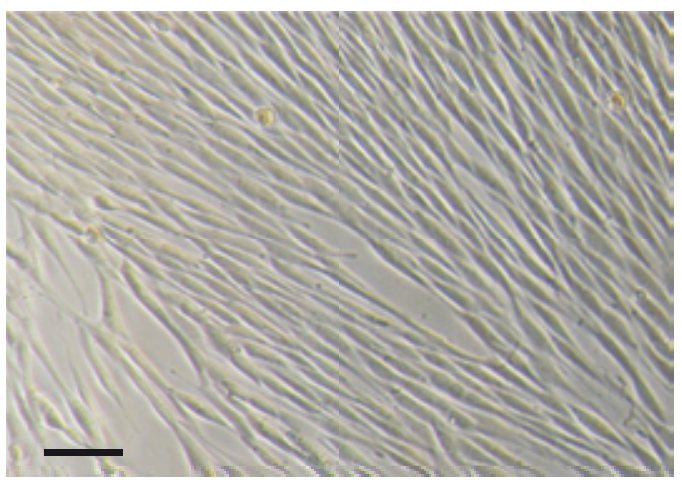

C

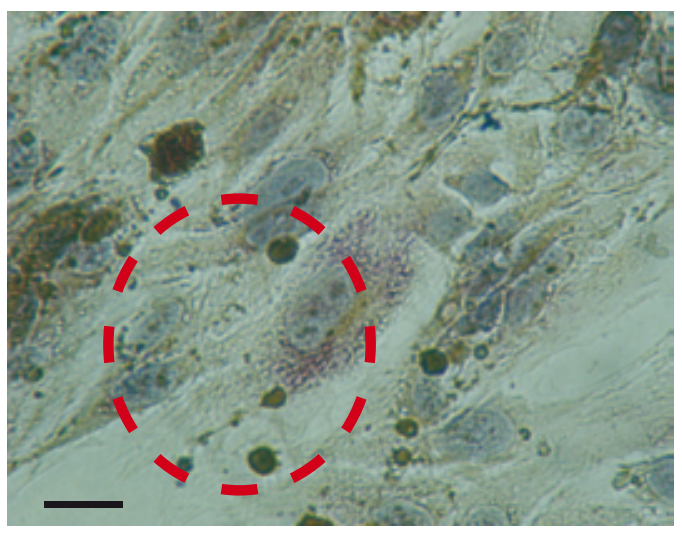

FIGURA 1. Imágenes de microscopio invertido de cajas de cultivo conteniendo: A) Progenitores de la médula ósea en medio 60:40 y SFB a $2 \%$ (control) después de diez días de cultivo, sin coloración. B) Progenitores de la médula ósea en medio con factores de diferenciación (10 ng/ml de M-CSF y $100 \mathrm{ng} / \mathrm{ml}$ del ligando del receptor activador del factor nuclear-kB o RANKL) sobre Thermanox (Th), coloración TRAP positiva, después de cinco días de cultivo y C) después de diez días de cultivo. D) Macrófagos en medio con factores de diferenciación después de diez días de cultivo sobre Th y coloración de TRAP positiva. Barra 200 micras. con los mismos factores de diferenciación. Las figuras $2 \mathrm{~A}$ y $2 \mathrm{~B}$ corresponden a las células de los controles negativos (línea de fibroblastos) y a los cultivos no inducidos, donde no se observan células con más de dos núcleos TRAP positivas.

Por SEM se confirmó la presencia de células gigantes al observar los cultivos inducidos sobre Th, láminas de PEBD y láminas de PEBD-CAp. En Th y PEBD las células con una confluencia mayor al $80 \%$ se observan electro-difusas y con tamaños de más de 100 micras (Figura 3A y B). En PEBD-CAp las células de los cultivos con una confluencia superior a $80 \%$ son electro-densas en su mayoría, sobresaliendo estructuras semejantes a islas que corresponden a aglomerados grandes de CAp en medio del cultivo confluente, en donde es posible visualizar células
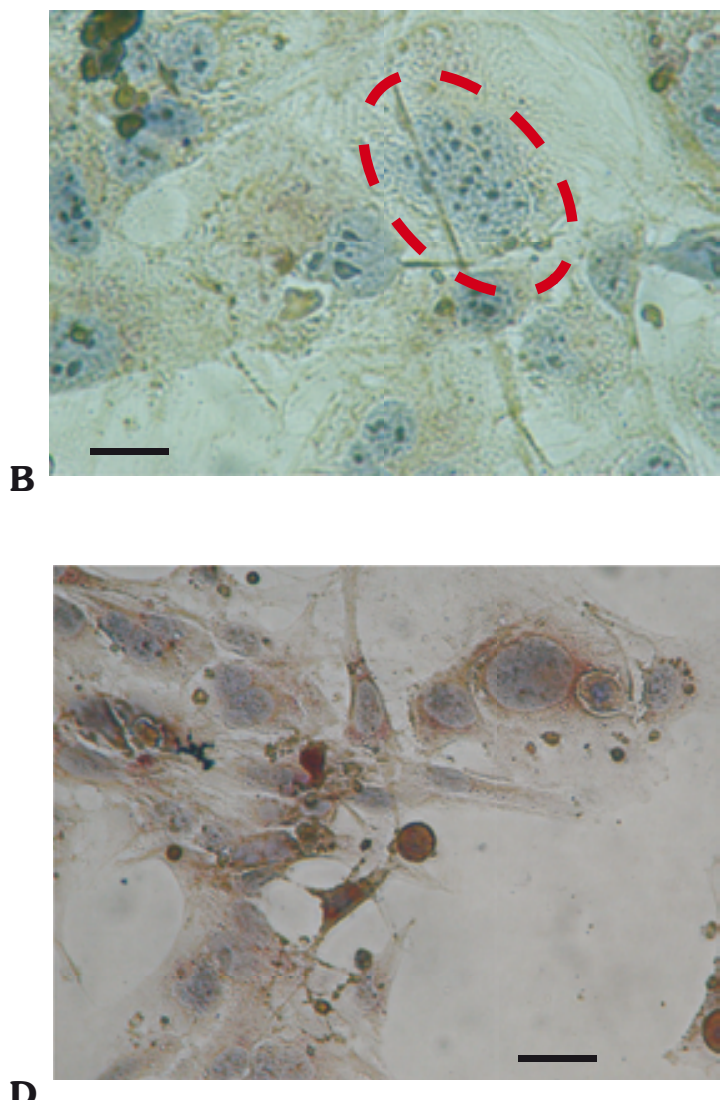

D 
A

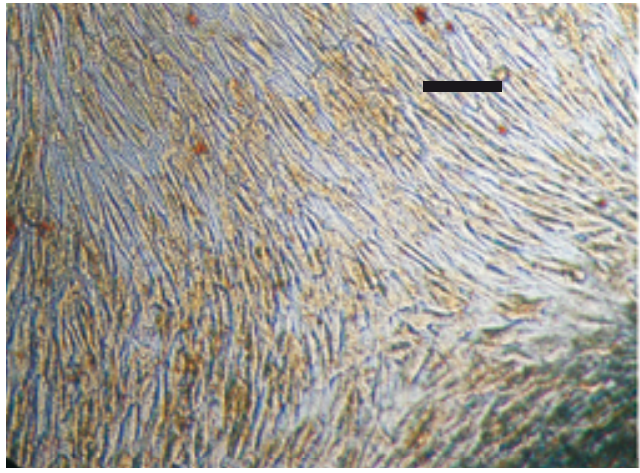

B

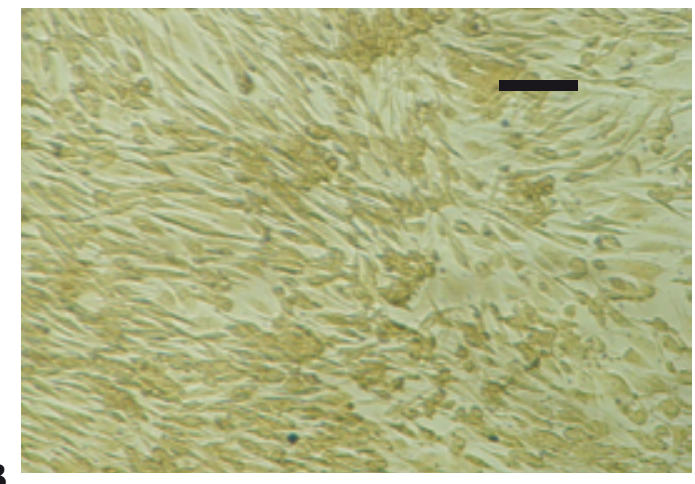

FIGURA 2. Imágenes de microscopio invertido de los controles sobre Thermanox (Th), después de diez días de cultivo y coloración TRAP negativa para cajas de cultivo conteniendo: A) Progenitores de la médula ósea en medio 60:40 y SFB 2\% y B) Fibroblastos en medio con factores de diferenciación (10 ng/ml de M-CSF y 100 ng/ml de RANKL). Barra 200 micras.

solitarias sobre CAp, moderadamente electro-densas y los efectos de la acción osteoclástica sobre los conglomerados de la cerámica (Figura 3C). Los osteoclastos parecen ser capaces de resorber CAp, ya que se observan numerosas zonas donde el material perece estar degradado (zonas de resorción). En estas zonas la morfología de las partículas y los espacios entre las mismas son diferentes cuando se comparan imágenes de microscopía óptica y microscopía electrónica del material con medio de cultivo (Figura 4), con el material más células en diferenciación osteoclástica (Figura 5).
Al comparar la morfología de los aglomerados de CAp en las áreas donde hay células con las áreas donde no hay células, se pueden ver diferencias morfológicas en el material, el cual se vio degradado (Figura $5 \mathrm{~A}-\mathrm{C}$ ). En los cultivos en los que se utilizó PEBD-CAp se pudo observar áreas con una aparente reabsorción alrededor de lo que se asemeja a las zonas de sellado o lagunas de reabsorción de osteoclastos (señalizadas con flechas en Figura 5D).

También se pueden observar márgenes regulares de las lagunas de resorción, en donde el material cerámico

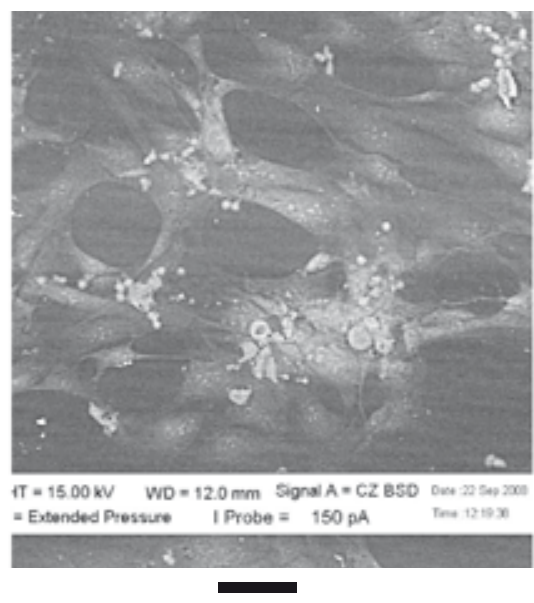

A

100 micras

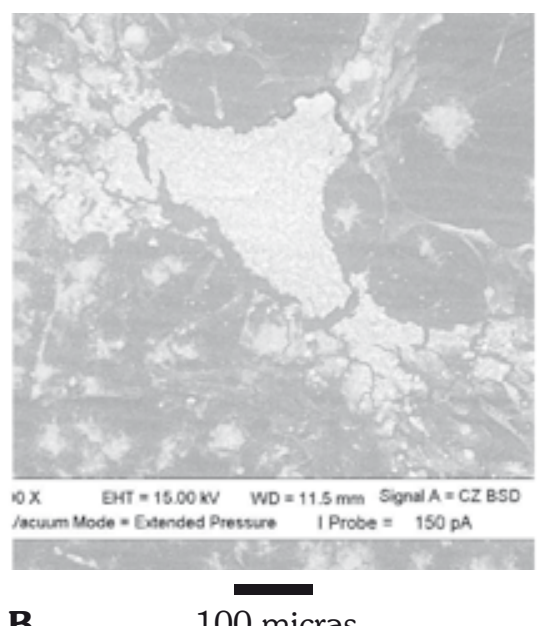

100 micras

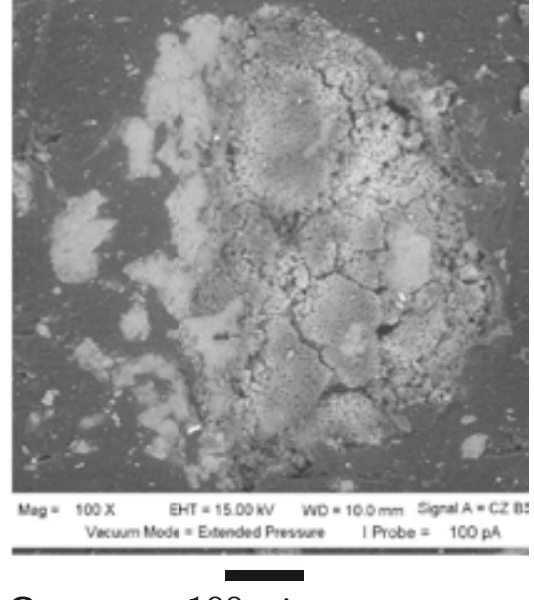

C

100 micras

FIGURA 3. Imágenes de SEM de cultivos inducidos con factores de diferenciación sobre: A) Thermanox (Th), destacando estructuras electro difusas (blanco y grises) correspondientes a células y estructuras electro densas (negro) correspondientes a Th; B) Polietileno de baja densidad (PEBD) donde las estructuras electro difusas (blanco) corresponden a células y las electro densas (gris oscuro) corresponden a PEBD; C) Compuesto de polietileno de baja densidad y apatita carbonatada (PEBD-CAp), donde las estructuras electro difusas (blanco) corresponden a un gránulo de CAp y los tonos de gris a una célula sobre CAp, mientras las estructuras electro densas (negro) corresponden a células en confluencia cubriendo el sustrato. 

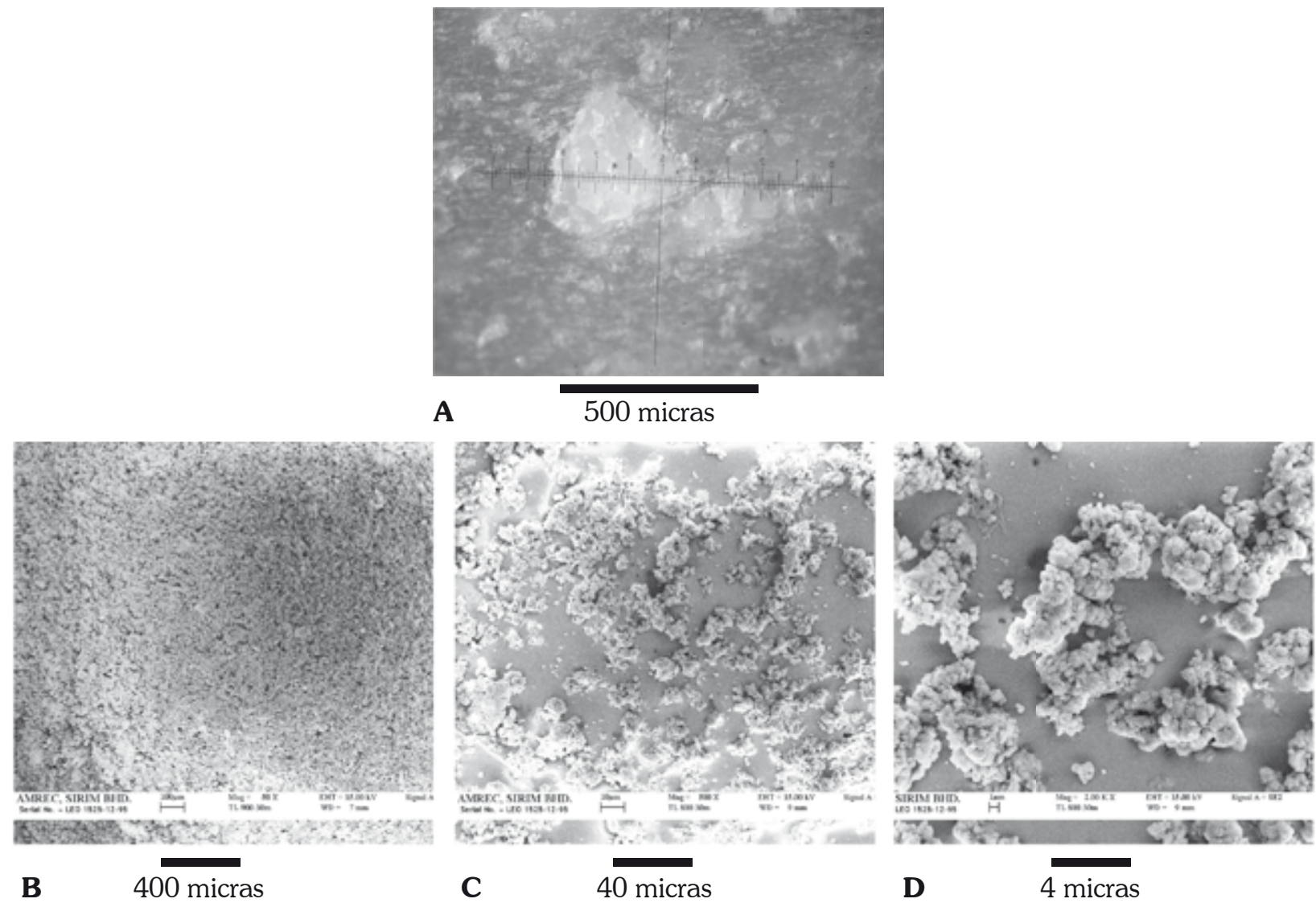

FIGURA 4. Imágenes de microscopia de la superficie del material de polietileno de baja densidad y apatita carbonatada (PEBD-CAp) sin células, donde se destaca: A) el tamaño de aglomerados grandes de CAp dispersos en PEBD en microscopio óptico, con diámetros alrededor de 500 a 300 micras (regla de $1 \mathrm{~mm}$ ); y aglomerados de menor tamaño (diámetros de 50 a 4 micras), cuya la morfología y disposición pueden apreciarse en microscopia electrónica de barrido- SEM (B a D).

ha desaparecido, y el tamaño y la forma corresponden a los de los bordes en cepillo de los osteoclastos en la fase resortiva (Figuras $5 \mathrm{E}$ y $\mathrm{F}$ ).

Los transcritos para los genes c-src (336pb), rank (528 $\mathrm{pb})$, y cat-K (615 pb) se detectaron a los cinco y diez días de cultivo de las células progenitoras de médula ósea inducidas, así como en la línea celular de macrófagos usada como control positivo (Figura 6).

\section{Discusión}

Con la utilización del modelo de cultivo establecido en los trabajos anteriores $(10,11,14,16)$, se ha logrado obtener la diferenciación de células progenitoras de la médula ósea de porcinos en células multinucledas con actividad fosfatasa ácida tartrato resistente, que expresan marcadores moleculares y muestran una actividad biológica semejante a la de los osteoclastos, resultados que son comparables con los de otros trabajos realizados con células de la médula de porcino y de otros mamíferos $(19,20,21)$. Los resultados confirman la importancia de M-CSF y RANK-L en la inducción de osteoclastos, hecho que se reporta en la literatura y que en conjunto con la sialoproteína ósea y la osteopontina, juegan un papel fundamental en la proliferación de las células progenitoras, en la expresión de genes que son marcadores de los osteoclastos y en la supervivencia y diferenciación a osteoclastos maduros $(19,22)$.

En lo relacionado con la producción de un material compuesto, se presentan resultados en donde se utilizó un material cerámico de CAp en polvo y un polímero, 


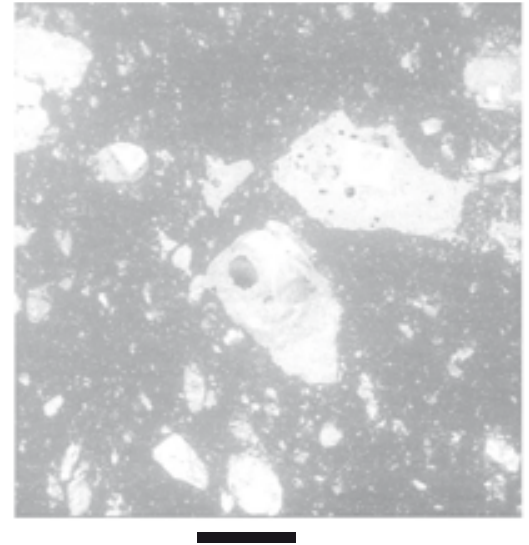

A
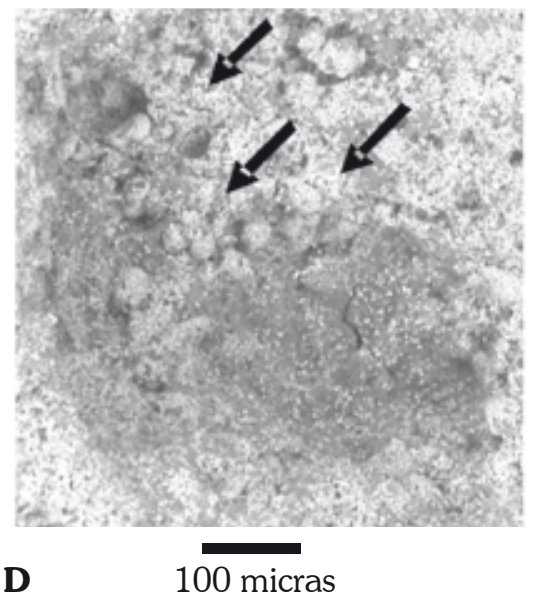

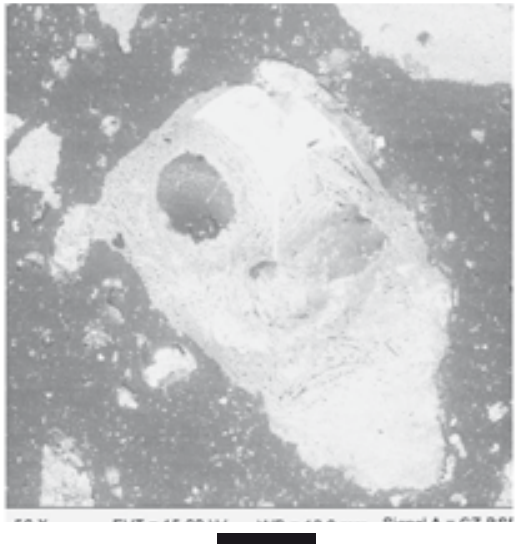

B

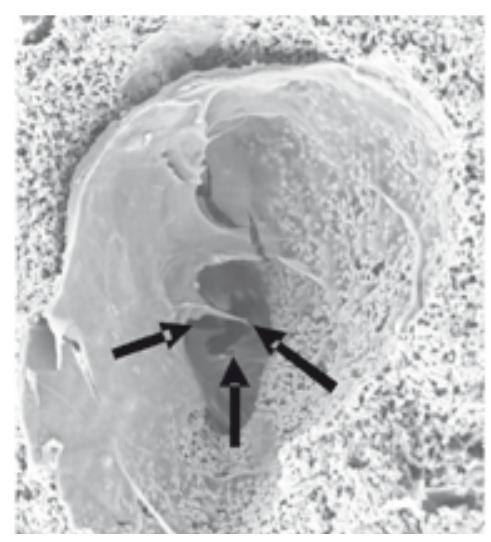

E

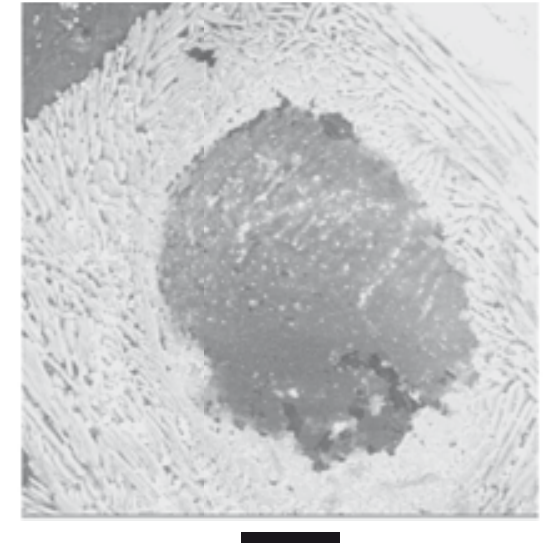

C

40 micras

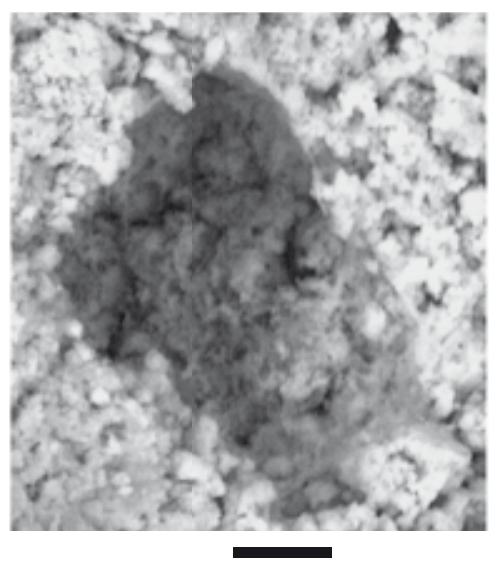

$\mathbf{F}$

10 micras

FIGURA 5. Imágenes de SEM de cultivos inducidos sobre PEBD-CAp donde se evidencia la acción de las células sobre los aglomerados grandes de CAp (A-C). Se destacan las zonas de resorción de CAp y el cambio en la morfología de los aglomerados en zonas especificas de las células, que corresponderían a zonas de sellado de los osteoclastos (Flechas D). Se destaca una laguna de resorción a 50 micras (E) y su detalle a 10 micras $(F)$.

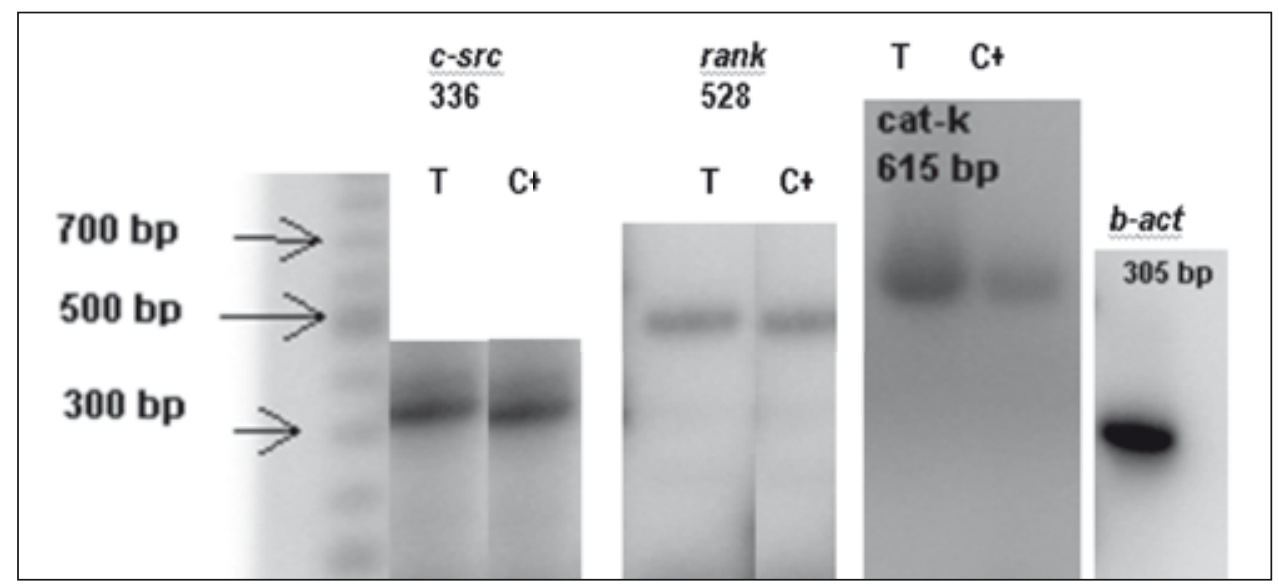

FIGURA 6. Detección de transcritos para los genes c-src (336 pb), rank (528 pb), y cat-K (615 pb). Los transcritos se detectaron a los en los días 5 y 10 de cultivo de progenitores de medula inducidos (T), así como en la línea celular de macró-fagos usada como control positivo $(C+)$. Como control positivo de extracción de ARN y síntesis de cADN fue la beta-actina (305 pb). 
con indicios muy prometedores de que esta cerámica puede ser remodelada de la misma forma que el mineral del hueso natural, que es resistente y no se disuelve a pH fisiológico. Estos resultados complementan los obtenidos en trabajos previos, en donde se sintetizó y caracterizó la cerámica CAp en otras presentaciones, y se demostró que ese material tiene capacidad osteoconductiva (11).

Además, la detección de transcritos de genes está en concordancia con la expresión de TRAP y los de otros marcadores de diferenciación osteoclástica, que se suman a la visualización de la resorción de CAp en las láminas PEBD-CAp sintetizadas para evidenciar la acción biológica de los osteoclastos.

En conclusión, la inducción de las células progenitoras de médula ósea de porcinos hacia el linaje osteoclástico utilizando inductores específicos y su utilización sobre el material compuesto (PEBD-CAp) sintetizado, permitió evidenciar una actividad osteoclástica sobre la cerámica, al observar su degradación por actividad celular a los diez días de cultivo, lo que se suma a la evidencia de su osteoconductividad en un modelo in vitro con osteoblastos porcinos (11) y su biodegradabilidad in vivo (23).

\section{Agradecimientos}

Los autores agradecen al Ministerio de Ciencia, Tecnología e Innovación de Malasia por la financiación de la investigación IRPA0901010031 EA001, a Sirim Berhad y a la Universidad Militar Nueva Granada, Fondo de investigaciones, por la financiación del proyecto MED -053.

\section{Bibliografía}

1. Lafita J. Fisiología y Fisiopatología Ósea. Anales del Sistema Sanitario de Navarra. 2003;26 (3):7-15.

2. Riancho J. Factores Reguladores de la Resorción Ósea. Revista Metabolismo Óseo y Mineral. 2003;1(2): 51-60.

3. Grigoriadis A, Wang Z Q, Cecchini M G. C-Fos: A Key Regulator of Osteoclast-macrophage Lineage Determination and Bone Remodeling. Science. 1994;266:443-448.

4. Hsu H, Lacey D, Dunstan C. Tumor Necrosis Factor Receptor Family Member RANK Mediates Osteoclast Differentiation and Activation Induced by Osteoprogeterin Ligand. Proceedings of the National Academy of Sciences. 1999;96(7):3540-3545.

5. Mikan J, Oliveros W. Osteoclastogenesis y Enfermedades Óseas. Revista Med. 2007;15(2):261-270.
6. Mariñoso M, Serrano S. Biopsia Ósea. En: Manual Práctico de Osteoporosis y Enfermedades del Metabolismo Mineral. Madrid. 2004:71-76.

7. Lacey D L. Osteoprotegerin Ligand is a Cytokine that Regulates Osteoclast Differentiation and Activation. Cell. 1998;93:165-76.

8. Riancho J, Gutierrez G. Factores Reguladores de la Resorción Ósea. Revista Metabolismo Óseo y Mineral. 2003;1(2):51-60.

9. Wu X, Pan G. RANKL Regulates Fas Expression and Fasmediated Apoptosis in Osteoclasts. Journal of Bone and Mineral Research. 2005;20(1):107-116.

10. Díaz L M, Villamil M, Bernal C L, Torres M L. Cultivo de Células de Linaje Osteogénico de Periostio de Porcino para la Evaluación de un Biomaterial. Revista Med. 2007;15(2):192-206.

11. Carretero C, Bernal C, Torres M. Evaluación de la Biocompatibilidad de Apatita Carbonatada de Síntesis seca por Medio del Cultivo de Células Osteoprogenitoras de Porcino. Revista Med. 2009;17(2):331-244

12. Maitz M F, Pham M T. Cell Culture Investigation of Implant Materials. Annual Report IIM 2000, FZR-314: 39-41. Documento recuperado el 13 de Abril de 2010 de: http://www.fzd. de/publications/003897/maitz.pdf.

13. ASIN, A. (2004). Estudio de Diferentes Formulaciones de Cementos de Fosfato de Calcio para Regeneración Ósea. Tesis Doctoral, Universidad Politécnica de Cataluña. Documento Recuperado el 13 de abril de 2010 de: http://bibliotecnica.upc. es/PFC/arxius/migrats/34101-1.pdf

14. Mikan J, Villamil M, Montes T. A Porcine Model for a Hybrid Material of Carbonated Apatite and Osteoprogenitor Cells. Materials Research Innovations. 2009;13(3):323-326.

15. Zakaria F A, Thevi K J, Abu Bakar. Preparation of Carbonated Apatite and its Evaluation. Proceedings of the Materials and Processes for Medical Devices Conference. 2005:14-16, Boston, Massachusetts, USA: ASM International. 2006:43-47.

16. Zakaria F A, Marsad N H, Abdul-Manaf A Y. Characterisation of Carbonated Apatite for Possible Application in Biomedical Implants. Materials Research Innovations. 2009;13(3):309-312.

17. Pierce A M, Lindskog S, Hammarström L. Osteoclasts: Structure and Function. Electron Microscopy Reviews. 1991;4:1-45.

18. Pittenger M, Mackay A, Beck S. Multipotential of Adult Human Mesenchymal "Stem" Cells. Science. 1999;284:143-147.

19. Scheven B A, Milne J S. A Novel Culture System to Generate Osteoclast and Bone Resorption using Porcine Bone Marrow Cells: Role of M-CSF. Biochemical and Biophysical Research Communications. 1997;231:231-235

20. Langstaff S, Sayer M, Smith T, Pugh S. Resorbable Bioceramics based on Stabilized Calcium Phosphates. Part II: Evaluation of Biological Response. Biomaterials. 2001;22:135-150.

21. Li Y J, Kim T H, Kwak HB, Lee ZH. Chloroform Extract of Deer Antler Inhibits Osteoclast Differentiation and Bone Resorption. Journal of Ethnopharmacology. 2007;113:191-198.

22. Malaval L, Wade-Gueye N, Boudiffa M. Bone Sialoprotein Plays a Functional Role in Bone Formation and Osteoclastogenesis. The Journal of Experimental Medicine. 2008;205(5):1145-53.

23. Rodríguez E, Pinzón L, Garzón D. Análisis Histológico de Implantes de Material Poroso de Apatita Carbonatada de Síntesis Seca y Células de Médula Ósea en un Modelo Porcino. En prensa Revista Med 2010. 